\title{
Uterine Tamponade Using Condom Catheter Balloon in The Management of Non-Traumatic Postpartum Hemorrhage
}

Mohammed Khaled Mostafa, Abd El-Samea Hassan Khalifa, and Mohammed Shaaban Hamid Rady*

Department of Obstetrics and Gynecology, Faculty of Medicine, Al-Azhar University

*Corresponding author: Mohammed Shaaban Rady, Mobile: (+20)01272324339, E-Mail: mohammed rady480@ gmail.com

\begin{abstract}
Background: uterine tamponade can be lifesaving in PPH associated with deranged coagulation; as such women are at high risk for surgical intervention or angiographic embolisation. Successful tamponade with Rusch balloon catheter, Sengstaken-Blakemore tube, rolled gauze and recently with condom catheter are reported.

Objective: the aim of this research was to study the efficacy and complications of uterine tamponade using condom catheter balloon in non-traumatic postpartum hemorrhage.

Patients and Methods: this single-arm prospective study, that was conducted in Kafr Al-Dawar General Hospital and Al-Hussein Hospital. Twenty patients with non-traumatic postpartum hemorrhage not responding to medical treatment were included in this study.

Results: outcome measures were the success rate in controlling hemorrhage, time required to stop bleeding, need for additional surgical measure, use of anesthesia, subsequent morbidity in terms of infection (measured by fever, total leucocyte counts $>12000 \mathrm{~mm} 3$ over next 5 days) and technical difficulties. There was significant statistical relation between volume of fluid in condom tamponade and pain in relation to the success in control of PPH in 15 $\min (\mathrm{P}<0.05)$. There was no significant statistical relation between age, gestational age, Parity, fever and total leucocytes count in relation to the success in control of PPH in $15 \mathrm{~min}(\mathrm{P}>0.05)$.

Conclusion: condom catheters control PPH effectively and quickly. It is a simple, inexpensive and safe method of conserving the reproductive capacity along with saving the life of women with primary PPH.
\end{abstract}

Keywords: Uterine tamponade, Condom catheter balloon, Non-traumatic postpartum hemorrhage

\section{INTRODUCTION}

Normal labor includes 4 stages: The 1st stage begins with the onset of labor and ends with full cervical dilation followed by the 2 nd stage of labor including the interval between full cervical dilation and the delivery of the infant, then the 3rd stage of labor which is the duration from the birth of the infant to the delivery of the placenta, umbilical cord and fetal membranes, the 4th stage or puerperium follows delivery and concludes with the resolution of the physiologic changes of pregnancy usually by 6 weeks postpartum in which the reproductive tract returns to the non-pregnant state and ovulation may resume ${ }^{(1)}$.

During the third stage of labor complications are common and can threaten the mother's life. The most common complication is postpartum hemorrhages (PPH), which remains a leading cause of maternal mortality, especially in developing countries (25.0\%), with placental retention and uterine atony are underlying causes of prolonged 3rd stage leading to postpartum hemorrhage. Women who survive PPH are likely to suffer from anemia and other complications ${ }^{(2)}$.

The common causes of PPH are referred to as the 'Four T's' and in order of most to least commonly occurring are ${ }^{(3)}:$ 1-Tone $(70 \%)$ : Atonic uterus, 2Trauma (20\%): Lacerations of the cervix, vagina and perineum, Extension lacerations at CS, Uterine rupture or inversion, 3-Tissue (10\%): Retained products, placenta (cotyledon or succenturiate lobe), membranes or clots, abnormal placenta and 4-
Thrombin $(<1 \%)$ : Coagulation abnormalities ${ }^{(3)}$.

A tony is by far the most common cause of postpartum hemorrhage. Uterine contraction is essential for appropriate hemostasis, and disruption of this process can lead to significant bleeding. Uterine atony is the typical cause of postpartum hemorrhage that occurs in the first 4 hours after delivery. Guidelines for the management of postpartum hemorrhage (PPH) involve a stepwise approach including the exclusion of retained products and genital tract trauma. Uterine atony, which is the most common cause, is dealt with uterine rubbing and various uterotonic agents such as oxytocin, ergometrine, misoprostol and prostaglandin F2a (PGF2a) ${ }^{(4)}$.

Recently, uterine balloon tamponade has been added to this armamentarium in the management of $\mathrm{PPH}^{(5,6,7)}$, the purpose of this research is to evaluate the use of uterine balloon technique currently available for the management of $\mathrm{PPH}$.

Uterine packing is the most basic method described for tamponade ${ }^{(8)}$ and recently, balloon technology, using the principle of a fluid-filled structure exerting a tamponade effect to stop bleeding has been used in the management of atonic PPH. Successful results have been shown by many researchers using a Sengstaken-Blakemore tube, Rusch urologic balloon 5 or condom catheter balloon. Bakri Surgical Obstetric Silicone (SOS) balloon is specially designed to control obstetric hemorrhage using pressure and tamponade effect ${ }^{(4,9)}$. 


\section{AIM OF THE WORK}

The aim of this research is to study the efficacy and complications of uterine tamponade using condom catheter balloon in non-traumatic postpartum hemorrhage.

\section{PATIENTS AND METHODS}

Study Design: A single-arm prospective study.

Study Setting: The study was conducted in Kafr AlDawar General Hospital and Al Hussein University Hospital.

Sample Size: Twenty patients with non-traumatic postpartum hemorrhage not responding to medical treatment were included in this study.

\section{Written informed consent:}

An approval of the study was obtained from Al-Azhar University Academic and Ethical Committee. Every patient signed an informed written consent for acceptance of the operation.

\section{Inclusion criteria:}

- All women with atonic PPH who delivered vaginally after 28 weeks of gestation.

- Primary postpartum hemorrhage was defined as the loss of more than $500 \mathrm{ml}$ of blood within the first 24 hours of delivery or loss of any amount that is enough to cause hemodynamic instability in the mother or loss of more than $10 \%$ of the total blood volume.

- Failure of medical management: (defined as failure to control bleeding inspite of maximum dosage of uterotonic drugs, or the patient started deteriorating as evidenced by hemodynamic instability (pulse rate $>120$ bpm and systolic blood pressure $<90$ $\mathrm{mmHg}$ ) such that surgical intervention became necessary.

\section{Exclusion criteria:}

- Women with traumatic PPH.

- $\quad$ PPH due to coagulation defect.

Women with secondary PPH.

Women who delivered by caesarean section.

\section{Methods:}

Women with non-traumatic PPH were initially treated with appropriate uterotonic, which included:

- Oxytocin (I.V. bolus, $10 \mathrm{U}$; or infusion, $40 \mathrm{U}$ in 500 $\mathrm{mL}$ of $0.9 \%$ normal saline).

- Inj. Methylergometrine (0.25 mg I.V. / I.M., maximum five doses).

- Prostaglandins (PGs) (Tab PGE1 $800 \mathrm{mg}$ per rectal or inj. PGF2a intramuscular $0.25 \mathrm{mg}$ repeated every 15 min, maximum eight doses).

Failure of medical management is at this predefined point, uterine tamponade was applied using condom catheter balloon and continue for next $8-48 \mathrm{~h}$ if the bleeding controlled. If the bleeding wasn't controlled, surgical management proceeded.

Failure of tamponade is defined as inability to control hemorrhage in $15 \mathrm{~min}$.

Steps of uterine tamponade using condom catheter balloon:

- Bleeding due to local trauma or retained tissue in the uterus (clinical/Ultra Sound Guided) was excluded.

- Informed consent.

- The condom catheter balloon was prepared by tying a condom over the proximal end of a Foley catheter with silk.

- The anterior and posterior lips of the cervix were held with two separate sponge holding forceps.

- The condom catheter was gently inserted inside the uterine cavity digitally or with the sponge holder.

- The bulb of the Foley catheter was inflated.

- The condom catheter was connected to a saline bottle through i.v. infusion, set and filled with saline until bleeding was controlled and the balloon was visible in the cervical canal usually $200-600 \mathrm{ml}$ needed.

- When the bleeding stops, the outer end of the Foley catheter was clamped, tied with silk thread and mark the fundal level.

- The tamponade was continued for the next 8-48 h.

\section{Care after uterine tamponade:}

- Oxytocin infusion was given (40-120 U according to clinical condition) over the time of tamponade.

- Temperature, pulse, blood pressure, uterine fundal height, vaginal bleeding, urine output, and serum electrolytes were closely monitored.

- Prophylactic broad-spectrum antibiotic cover was given until the tamponade was in place.

\section{Removal of condom catheter balloon:}

- After 8-48 h, if there is no bleeding, the balloon was removed.

- Before removal of the tamponade, it was ensured that the patient is fasting and the coagulation profile was normal.

- Oxytocin infusion (20 Uin $500 \mathrm{~mL}$ saline) was started half an hour before deflation (if not already running).

- The balloon was deflated slowly, but not removed for $30 \mathrm{~min}$ so that it could be inflated again if bleeding restarts after deflation.

- If there is no bleeding for the next $30 \mathrm{~min}$, the catheter was removed and the oxytocin infusion continued according to clinical assessment, for a maximum $6 \mathrm{~h}$.

\section{Outcome Measures:}

- Success rate in controlling hemorrhage.

- Time required stopping bleeding.

- Need for additional surgical measure, use of 
anesthesia.

- Subsequent morbidity in terms of infection (measured by fever, total leucocyte counts >12 000 mm3 over next 5 days).

- Technical difficulties.

\section{Statistical analysis}

Recorded data were analyzed using the statistical package for social sciences, version 20.0 (SPSS Inc., Chicago, Illinois, USA). Quantitative data were expressed as mean \pm standard deviation (SD). Qualitative data were expressed as frequency and percentage.

\section{The following tests were done:}

- Independent-samples t-test of significance was used when comparing between two means.

Chi-square $\left(\mathrm{x}^{2}\right)$ test of significance was used in order to compare proportions between two qualitative parameters.
the margin of error accepted was set to $5 \%$. The $\mathrm{p}$ value was considered significant as the following:

Probability (P-value)

- P-value <0.05 was considered significant.

- $\quad$ P-value $<0.001$ was considered as highly significant.

- P-value $>0.05$ was considered insignificant.

\section{RESULTS}

This single-arm prospective study, that was conducted in Kafr Al-Dawar General Hospital and Al-Hussein University Hospital.

The present study was carried out to assess the efficacy of uterine tamponade using condom catheter balloon in treatment of atonic postpartum hemorrhage. Twenty patients with non-traumatic postpartum hemorrhage not responding to medical treatment were included in this study and results.

Table (1): Distribution of the studied patient's group regarding demographic data

\begin{tabular}{|c|c|c|}
\hline Variables & Number & Percent \\
\hline Age & & \\
\hline$<25$ & 9 & 45.0 \\
\hline $25-30$ & 7 & 35.0 \\
\hline $30+$ & 4 & 20.0 \\
\hline $\begin{array}{l}\text { Range } \\
\text { Mean } \pm \text { S.D. }\end{array}$ & \multicolumn{2}{|c|}{$\begin{array}{l}21.0-35.0 \\
24.2 \pm 4.2\end{array}$} \\
\hline \multicolumn{3}{|l|}{ Gestational age } \\
\hline$<37$ weeks & 9 & 45.0 \\
\hline$>37$ weeks & 11 & 55.0 \\
\hline $\begin{array}{l}\text { Range } \\
\text { Mean } \pm \text { S.D. }\end{array}$ & \multicolumn{2}{|c|}{$\begin{array}{l}32.0-40.0 \\
36.7 \pm 2.3 \\
\end{array}$} \\
\hline \multicolumn{3}{|l|}{ Parity } \\
\hline P0 & 4 & 20.0 \\
\hline $\mathrm{P} 1$ & 3 & 15.0 \\
\hline $\mathrm{P} 2-3$ & 10 & 50.0 \\
\hline $\mathrm{P} 4$ & 3 & 15.0 \\
\hline $\begin{array}{l}\text { Range } \\
\text { Mean } \pm \text { S.D. }\end{array}$ & \multicolumn{2}{|c|}{$\begin{array}{c}0.0-4.0 \\
1.95 \pm 1.3\end{array}$} \\
\hline
\end{tabular}

Table (1) shows distribution of the studied patient's group regarding demographic data. Age ranged from 21-35 with mean value $24.2 \pm 4.2$, gestational age ranged from $32-40$ with mean value $36.7 \pm 2.3$ and parity ranged from $0-4$ with mean value $1.95 \pm 1.3$.

Table (2): Distribution of the studied patients group regarding incidence of complications

\begin{tabular}{|c|c|c|}
\hline Variables & Number & Percent \\
\hline Fever & 6 & 30.0 \\
\hline Pain & 15 & 75.0 \\
\hline Total leucocyte $>12000 \mathrm{~mm} 3$ & 3 & 15.0 \\
\hline Need for blood transfusion & 3 & 15.0 \\
\hline
\end{tabular}

Table (2) shows distribution of the studied patient's group regarding incidence of complications. Pain was higher with $15(75 \%)$ followed by fever with six $(30 \%)$, total leucocyte was three $(15 \%)$ and need for blood transfusion was three $(15 \%)$. 
ejhm.journals.ekb.eg

Table (3): Age in relation to success in control of PPH in $15 \mathrm{~min}$

\begin{tabular}{|c|c|c|c|c|}
\hline \multirow{2}{*}{ Age category } & \multicolumn{4}{|c|}{ Success in control of PPH in 15 min } \\
\cline { 2 - 5 } & \multicolumn{3}{|c|}{ No } & \multicolumn{3}{c|}{ Yes } \\
\cline { 2 - 5 } & Number & Percent & Number & Percent \\
\hline$<25$ & 1 & 33.3 & 6 & 47.1 \\
\hline $\mathbf{2 5 - 3 0}$ & 1 & 33.3 & 3 & 17.3 \\
\hline $\mathbf{3 0 +}$ & 1 & 100.0 & 17 & 100.0 \\
\hline Total & 3 & 1.25 \\
\hline $\mathbf{X} 2$ & \multicolumn{5}{|c|}{0.456} \\
\hline
\end{tabular}

$\mathrm{X} 2=$ Chi square test, $\mathrm{P}$ is significant if $<0.05$

Table (3) shows age in relation to success in control of PPH in $15 \mathrm{~min}$. There was no statistical significant relation between age and success in control of $\mathrm{PPH}$ in $15 \mathrm{~min}(\mathrm{P}>0.05)$.

Table (4): Relation between gestational age and success in control of PPH in 15 min

\begin{tabular}{|c|c|c|c|c|}
\hline \multirow{2}{*}{ G.A. category } & \multicolumn{4}{|c|}{ Success in control of PPH in 15 min } \\
\cline { 2 - 5 } & \multicolumn{3}{|c|}{ No } & \multicolumn{3}{c|}{ Yes } \\
\cline { 2 - 5 } & Number & Percent & Number & Percent \\
\hline$<37$ weeks & 1 & 33.3 & 9 & 47.1 \\
\hline$>37$ weeks & 2 & 66.7 & 17 & 100.9 \\
\hline Total & 3 & 100.0 & 9.0 \\
\hline P & \multicolumn{3}{|c|}{0.03} \\
\hline
\end{tabular}

$\mathrm{X} 2=$ Chi square test, $\mathrm{P}$ is significant if $<0.05, *$ Significant

Table (4) shows relation between gestational age and success in control of PPH in 15 min. There was no statistical significant relation between gestational age and success in control of PPH in 15 min $(\mathrm{P}>0.05)$.

Table (5): Relation between parity and success in control of PPH in $15 \mathrm{~min}$

\begin{tabular}{|c|c|c|c|c|}
\hline \multirow{2}{*}{ Parity category } & \multicolumn{4}{|c|}{ Success in control of PPH in 15 min } \\
\cline { 2 - 5 } & \multicolumn{2}{|c|}{ No } & \multicolumn{2}{c|}{ Yes } \\
\cline { 2 - 5 } & Number & Percent & Number & Percent \\
\hline P0 & 1 & 33.3 & 3 & 17.6 \\
\hline P1 & 0 & 0.0 & 8 & 17.6 \\
\hline P2-3 & 2 & 0.0 & 3 & 17.1 \\
\hline P4 & 0 & 0.0 & 17 & 100.0 \\
\hline Potal & 3 & 100.0 & 3.6 \\
\hline X2 & \multicolumn{3}{|c|}{0.112} \\
\hline
\end{tabular}

$\mathrm{X} 2=$ Chi square test, $\mathrm{P}$ is significant if $<0.05$, * Significant

Table (5) shows relation between parity and success in control of PPH in $15 \mathrm{~min}$. There was no statistical significant relation between parity and success in control of PPH in $15 \min (\mathrm{P}>0.05)$.

Table (6): Relation between Volume of fluid in condom tamponade and success in control of PPH in 15 min

\begin{tabular}{|c|c|c|c|c|}
\hline \multirow{2}{*}{ Volume of fluid in condom tamponade } & \multicolumn{3}{|c|}{ Success in control of PPH in 15 min } \\
\cline { 2 - 5 } & \multicolumn{3}{|c|}{ No } & \multicolumn{3}{c|}{ Yes } \\
\cline { 2 - 5 } & Number & Percent & Number & Percent \\
\hline $\mathbf{3 0 0} \mathbf{~ m l}$ & 0 & 0.0 & 5 & 29.4 \\
\hline $\mathbf{3 0 0 - 4 0 0} \mathbf{~ m l}$ & 0 & 0.0 & 8 & 47.1 \\
\hline $\mathbf{4 0 0 +} \mathbf{~ m l}$ & 3 & 100.0 & 4 & 23.5 \\
\hline Total & 3 & 100.0 & 17 & 100.0 \\
\hline $\mathbf{P}$ & \multicolumn{4}{|c|}{6.555} \\
\hline $\mathbf{X} 2$ & \multicolumn{4}{|c|}{$0.038^{*}$} \\
\hline
\end{tabular}

$\mathrm{X} 2=$ Chi square test, $\mathrm{P}$ is significant if $<0.05, *$ Significant. Table (6) shows relation between Volume of fluid in condom tamponade and success in control of PPH in $15 \mathrm{~min}$. There was statistical significant relation between Volume of fluid in condom tamponade and success in control of PPH in $15 \min (\mathrm{P}<0.05)$. 
ejhm.journals.ekb.eg

Table (7): Relation between fever and success in control of PPH in 15 min

\begin{tabular}{|c|c|c|c|c|}
\hline \multirow{2}{*}{ Fever } & \multicolumn{5}{|c|}{ Success in control of PPH in 15 min } \\
\cline { 2 - 5 } & Number & Percent & Number & Percent \\
\cline { 2 - 5 } & 1 & 33.3 & 13 & 76.5 \\
\hline No & 2 & 66.7 & 4 & 23.5 \\
\hline Yes & 3 & 100.0 & 17 & 100.0 \\
\hline Total & \multicolumn{3}{|c|}{2.260} \\
\hline P & \multicolumn{5}{|c|}{0.133} \\
X2 & \multicolumn{3}{|c|}{} \\
\hline
\end{tabular}

$\mathrm{X} 2=$ Chi square test, $\mathrm{P}$ is significant if $<0.05$

Table (7) shows relation between fever and success in control of PPH in $15 \mathrm{~min}$. There was no statistical significant relation between fever and success in control of PPH in 15 min $(\mathrm{P}<0.05)$.

Table (8): Relation between pain and success in control of PPH in 15 min

\begin{tabular}{|c|c|c|c|c|}
\hline \multirow{3}{*}{ Pain } & \multicolumn{4}{|c|}{ Success in control of PPH in 15 min } \\
\cline { 2 - 5 } & No & Nercent & Number & Percent \\
\cline { 2 - 5 } & Number & 0.0 & 15 & 88.2 \\
\hline No & 0 & 100.0 & 2 & 11.8 \\
\hline Yes & 3 & 100.0 & 17 & 88.2 \\
\hline Total & 3 & 10.588 \\
P & \multicolumn{3}{|c|}{$0.001^{*}$} \\
X2 & \multicolumn{3}{|c|}{} \\
\hline
\end{tabular}

$\mathrm{X} 2=$ Chi square test, $\mathrm{P}$ is significant if $<0.05, *$ Significant

Table (8) shows relation between pain and success in control of PPH in $15 \mathrm{~min}$. There was statistical significant relation between pain and success in control of PPH in 15 min.

\section{DISCUSSION}

The present study was carried out to assess the efficacy of uterine tamponade using condom catheter balloon in treatment of atonic postpartum hemorrhage. Twenty patients with non-traumatic postpartum hemorrhage not responding to medical treatment were included in this study.

As regard the success of control of $\mathrm{PPH}$ within 15 min., Success cases were seventeen $(85 \%)$ and failed were three $(15 \%)$. The three patient in whom the balloon use failed to control PPH needed surgical intervention. In the three failed cases, technical difficulties led to placement failure in one case ended by laparotomy and bilateral uterine ligation and B Lynch sutures, posterior wall fibroid in the other that ended by hysterectomy on patient and relatives demand due to inter menstrual bleeding before pregnancy and recurrence of bleeding in the third after few minutes and elevation of fundal level that ended by bilateral uterine and internal iliac artery ligation.

As regard the relation between Volume of fluid in condom tamponade and success in control of $\mathrm{PPH}$ in $15 \mathrm{~min}$. There was statistical significant relation between Volume of fluid in condom tamponade and success in control of PPH in $15 \mathrm{~min}$ $(\mathrm{P}<0.05)$.

As regard the relation between pain and success in control of $\mathrm{PPH}$ in $15 \mathrm{~min}$. There was statistical significant relation between pain and success in control of PPH in $15 \mathrm{~min}$.

As regard the age in relation to success in control of PPH in $15 \mathrm{~min}$. There was no statistical significant relation between age and success in control of PPH in $15 \mathrm{~min}(\mathrm{P}>0.05)$.

As regard the relation between gestational age and success in control of PPH in 15 min. There was no statistical significant relation between gestational age and success in control of PPH in 15 $\min (\mathrm{P}>0.05)$.

As regard the relation between parity and success in control of PPH in $15 \mathrm{~min}$. There was no statistical significant relation between parity and success in control of PPH in $15 \mathrm{~min}(\mathrm{P}>0.05)$.

As regard the relation between fever and success in control of PPH in $15 \mathrm{~min}$. There was no statistical significant relation between fever and success in control of PPH in $15 \mathrm{~min}(\mathrm{P}<0.05)$.

In agreement with the current findings, a case series reported that $23 \mathrm{PPH}$ patients unresponsive to medical therapy were managed with intrauterine balloon tamponade. When properly placed, catheters controlled PPH in 18 of 20 cases (90\%). In two cases, hysterectomy was required despite successful placement of the catheter. For haemorrhage due to uterine atony, the success rate was $100 \%(11 / 11$ cases). In three cases, technical difficulties led to placement failure. Thus, balloon tamponade is an 
effective adjunct in the treatment of severe $\mathrm{PPH}$, especially when due to uterine atony when medical therapy fails ${ }^{(\mathbf{1 0})}$.

Also Rathore et al. (11) reported that the success rate of condom catheter balloon in controlling hemorrhage was $94 \%$. The mean amount of fluid filled in the condom catheter balloon was $409 \mathrm{~mL}$. The average time taken to control bleeding was 6.2 min. The mean duration for which condom catheter balloon was left in situ was $27.5 \mathrm{~h}$. five patients (28\%) had infective morbidity ${ }^{(11)}$.

In partial agreement with the present study, Doumouchtsis et al. ${ }^{(12)}$ reported that there were 27 women who had placement of the catheter. In $22(81 \%)$ case hemostasis was achieved, while in $5(19 \%)$ cases the Sengstaken Blakemore esophageal catheter (SBOC) failed in arresting hemorrhage. Of the 5 failures, hysterectomy was required in 4 cases and in the remaining case the failure was associated with expulsion of the balloon, but hemostasis was achieved with further conservative measures. Among the failed cases, there was one maternal death due to amniotic fluid embolism with cardiac arrest and PPH secondary to coagulopathy. In cases where the balloon was successful, it was removed around 24 hours later. In these cases, no further bleeding was observed, and no complications occurred from the procedure.

As well in 2015, Seror et al. ${ }^{(7)}$, reported 17 patients with atony or retained products treated with balloon tamponade for postpartum bleeding who failed medical therapy. Bleeding was controlled in $71 \%$ of their patients.

In 2012, one prospective observational study evaluated the use of a uterine sandwich technique (uterine compression sutures in association with intrauterine tamponade) in women who had had unsuccessful medical treatment for PPH. Ten of the 11 patients had CS (complicated by placenta previa and uterine atony) and 1 had a normal delivery, respectively. B-Lynch sutures were placed in two patients and Hayman's modification was used in 9. Bakri balloon tamponade was in place for a median of 22 hours (range: 17-27 hours), while the median volume infused in the balloon was $300 \mathrm{ml}$ (range: $150-$ $350 \mathrm{ml})$. The combined technique was successful in avoiding hysterectomy in all cases, and there was no documented postpartum morbidity. This is a simple and quick surgical technique that can be used to treat atonic PPH, particularly in conjunction with placenta previa ${ }^{(13)}$.

\section{CONCLUSION}

Condom catheters control PPH effectively and quickly. It is a simple, inexpensive and safe method of conserving the reproductive capacity along with saving the life of women with primary $\mathrm{PPH}$.

\section{REFERENCES}

1. Cunningham FG, Gant NF and Leveno KJ (2014): Williams Obstetrics. 24 ${ }^{\text {th }}$ ed. New York, NY: McGrawHill., Pp. 320-5.

2. Chamberlain $\mathbf{G}$ (2010): The clinical aspects of massive haemorrhage. In: Patel N (ed.) Maternal mortality the way forward. London (UK): Royal College of Obstetricians and Gynecologists, Pp. 54-62.

3. Royal College of Obstetricians and Gynaecologists (2009): Prevention and management of postpartum haemorrhage. London.Selo-Ojeme DO (2002) Primary postpartum haemorrhage. J Obstet Gynaecol., 22: 463469.

4. Rather SY, Qadir A, Parveen S, Jabeen F (2010): Use of Condom to Control Intractable PPH. JK Science, 12: 127-129.

5. Bakri YN, Amri A, Abdul Jabbar F (2001): Tamponade balloon for obstetrical bleeding. Int $\mathrm{J}$ Gynecol Obstet., 74: 139-42.

6. Condous GS, Arulkumaran S, Symonds I, Chapman R, Sinha A, Razvi K (2003): The 'tamponade test' in the management of massive postpartum hemorrhage. Obstet Gynecol., 101:767-772.

7. Seror J, Allouche C, Elhaik S (2005): Use of Sengstaken-Blakemore tube in massive postpartum haemorrhage: A series of 17 cases. Acta Obstet Gynecol Scand., 84: 660-4.

8. Keriakos R, Mukhopadhyay A (2006): The use of the Rusch balloon for management of severe postpartum haemorrhage. J Obstet Gynaecol., 26:335-8.

9. Thapa K, Malla B, Pandey S, Amatya S (2010): Intrauterine condom tamponade in management of post partum haemorrhage. J Nepal Health Res Counc., 8: 1922.

10.Dabelea V, Schultze PM, McDuffie RS (2007): Intrauterine balloon tamponade in the management of postpartum hemorrhage. Am J Perinatol., 24:359-64.

11. Rathore AM, Gupta S, Manaktala U, Gupta S, Dubey C, Khan M (2012): Uterine tamponade using condom catheter balloon in the managementofnon-traumatic postpartum hemorrhage. J Obstet Gynaecol Res., 38:1162-7.

12.Doumouchtsis SK, Papageorghiou AT, Vernier C, Arulkumaran S (2008): Management of postpartum hemorrhage by uterine balloon tamponade: prospective evaluation of effectiveness. Acta Obstet Gynecol Scand., 87:849-55.

13. Yoong W, Ridout A, Memtsa M, Stavroulis A, ArefAdib M, Ramsay Marcelle Z (2012): Application of uterine compression suture in association with intrauterine balloon tamponade ('uterine sandwich') for postpartum hemorrhage. Acta Obstet Gynecol Scand., 91:147-51. 